\title{
Ein deutscher Jung-Manager in Rußland
}

\author{
Thomas Bär ${ }^{*}$
}

\section{Werdegang}

Nach dem Abitur (mit Schwerpunkt Russisch) und einer dreijährigen Wehrdienstzeit habe ich mein Studium an der Technischen Universität ChemnitzZwickau aufgenommen. Dabei habe ich mich in den Bereichen Marketing, Organisation und Russische Sprache spezialisiert. In den Jahren des Studiums habe ich verschiedene Praktika (u.a. bei einer Firma in Nishnij Novgorod) absolviert sowie ein halbjähriges Studium in Rußland (an der St. Petersburger Universität für Ökonomie und Finanzen) absolviert.

Bereits vor Abschluß meines Diploms habe ich im Februar 1995 eine Stelle als Assistent der Geschäftsführung eines deutschen Cash\&Carry Marktes in St. Petersburg angetreten. Ab Juli 1995 übernahm ich die Funktion des Geschäftsführers, die ich bis Mai 1996 innehatte. Zu diesem Zeitpunkt habe ich mich selbständig gemacht und leite nun parallel drei Firmen in den Bereichen Lebensmittelhandel, Fensterproduktion und Consulting.

\section{Probleme}

Bei meiner Tätigkeit wurde ich mit einer Reihe von gravierenden Problemen konfrontiert: Die Gesetzgebung in Rußland ist einem ständigen Wandel unterworfen, was eine längerfristige Unternehmensplanung sehr erschwert. (An dieser Stelle muß allerdings vermerkt werden, daß diese Situation der Unsicherheit für meine Consultingfirma natürlich ein Plus darstellt.) Verbunden damit ist auch eine beträchtliche Behördenwillkür zu verzeichnen.

Im weiteren läßt die Zahlungsmoral vieler Kunden sehr zu wünschen übrig. In vielen Unternehmensbereichen herrscht auch ein Übermaß an Papierkrieg, der die wichtigen Funktionen behindert.

Thomas Bär, geb. 1968, Geschäftsführer von drei Firmen in den Bereichen Lebensmittelhandel, Fensterproduktion und Consulting in St. Petersburg. 


\section{Tendenzen}

Nach der erfolgreichen Wiederwahl von Präsident Jelzin rechne ich mit einer verstärkten Investitionstätigkeit ausländischer Firmen in Rußland; in diesem Bereich könnte es zu einem eigentlichen Boom kommen.

Im Bereich des Lebensmittelhandels wird die Einführung von Importkontingenten ein wichtiger Einflußfaktor werden. Im Bereich der Zölle erwarte ich eine deutliche Senkung der Sätze für Investitionsgüter, was natürlich die Investitionstätigkeit (speziell ausländischer Firmen) weiter ankurbeln soll.

\section{Empfehlungen}

Wer heute in Rußland unternehmerisch tätig werden will, der sollte in erster Linie über ausgezeichnete Kenntnisse der russischen Sprache verfügen. Um die (Geschäfts-)Gepflogenheiten des Landes kennenzulernen empfiehlt sich darüber hinaus die vorgängige Absolvierung von Praktikas; manche Fehler, die man hier - noch einigermaßen schadlos - begeht, können später viel Geld kosten.

$\mathrm{Zu}$ guter letzt ist die Suche nach geeigneten Geschäftspartnern unumgänglich. Diese sollten nicht nur über etwas Kapital verfügen, wichtig ist vor allem, daß man ihnen vertrauen kann. 